\title{
Semen quality trends in French regions are consistent with a global change in environmental exposure
}

\author{
Joëlle Le Moal, Matthieu Rolland, Sarah Goria, Vérène Wagner, Perrine De Crouy-Chanel, \\ Annabel Rigou, Jacques De Mouzon ${ }^{1,2}$ and Dominique Royère ${ }^{1}$ \\ Environmental Health Department, Institut de Veille Sanitaire, 12 Rue du Val d'Osne, 94415 Saint Maurice, France, \\ ${ }^{1}$ Fivnat, Reproductive Biology Unit, CHU Bretonnneau, 37000 Tours, France and ${ }^{2}$ Inserm, Reproductive Medicine \\ Unit, Paris-Descartes University, CHU Cochin-Port Royal, 7414 Paris, France
}

Correspondence should be addressed to J Le Moal; Email: j.lemoal@invs.sante.fr

\begin{abstract}
A retrospective study carried out recently in a large sample of men, close to the general population, has reported a significant and strong decline in sperm concentration and morphology in the whole of France between 1989 and 2005 . We studied these trends within each region of France. Data were obtained from the Fivnat database. The study sample comprised male partners of sterile women in whom both tubes were absent or blocked. They were located at the assisted reproductive technology center. A Bayesian spatio-temporal model with parametric time trends, adjusted for age, was used to model overall time trends for each region. The results show that sperm concentration decreased in almost all regions of France. Among them, Aquitaine showed the highest decrease and Midi-Pyrénées had the lowest average for the whole period. Regarding total motility, most regions showed a slight increase while Bourgogne showed a steep and significant decrease. While considering sperm morphology, there was a decrease in most of the regions. The decrease in Aquitaine and Midi-Pyrénées was stronger when compared with the overall trend. In conclusion, a decrease in sperm concentration and morphology, already shown at the French metropolitan territory level, was observed in most regions of France. This is consistent with a global change in environmental exposure, according to the endocrine disruptor hypothesis especially. Indeed, ubiquitary exposure to chemicals has been growing in the general population of France since the 1950s, and the results do not appear to support the lifestyle hypothesis. The highest decreases and lowest values are consistently observed in two proximate regions that are both highly agricultural and densely populated.
\end{abstract}

Reproduction (2014) 147 567-574

\section{Introduction}

Temporal trends in human semen quality have been discussed for a long time, partly due to spatial heterogeneity (Jorgensen et al. 2001) and methodological issues (Fisch 2008).

Recently in France, an overall decrease in sperm concentration and morphology has been observed in

\footnotetext{
This paper forms part of a special issue of Reproduction on Endocrine Disrupters. This article was presented at the 7 th Copenhagen Workshop on Endocrine Disrupters, 28-31 May 2013. The meeting was supported by the Danish Ministry of the Environment - Environmental Protection Agency as an activity under the Danish Centre on Endocrine Disrupters. Publication of this special issue has been supported by the Society for Reproduction and Fertility. The opinions or views expressed in this special issue are those of the authors, and do not necessarily reflect the opinions or recommendations of the Danish Ministry of the Environment - Environmental Protection Agency or the Society for Reproduction and Fertility. The Guest Editors for this special issue were Anna-Maria Andersson, Hanne Frederiksen, Niels Erik Skakkebæk, Rigshospitalet, Denmark, Kenneth M Grigor, Western General Hospital, Edinburgh, UK and Jorma Toppari, University of Turku, Finland.
}

26609 men from the whole metropolitan country between 1989 and 2005. No decrease in motility was observed (Rolland et al. 2013). This sample of men close to the general population is, to date, the largest sample that has ever been used to study semen quality trends.

These results were consistent with the past studies in France (Auger et al. 1995) and in other countries (Carlsen et al. 1992, Swan et al. 1997) where decreasing temporal trends have been observed. These robust results regarding temporal trends constitute a serious public health warning. The endocrine disruptor hypothesis, strengthened by accumulating evidence lately (Bergman et al. 2012), may partly explain such trends. Changes in lifestyle are other identified factors (Sharpe 2010).

In the previous study, the trends were calculated at the level of the whole country, and did not take into account a possible spatial heterogeneity. Spatial heterogeneity has previously been observed in France in limited samples (Auger \& Jouannet 1997), as well as in Europe (Jorgensen et al. 2001) or in USA (Swan et al. 2003), but 
little is known about the causal factors. The present study aims to analyze spatial patterns in France between 1989 and 2005, using the same sample in which the global trends were calculated, in order to generate possible consistent hypotheses.

\section{Materials and methods}

\section{Source and study population}

Data were obtained from the Fivnat database, a national registry that recorded most of the French-assisted reproductive technology (ART) attempts during the study period. The study sample comprised partners of totally infertile women whose both tubes were either blocked or absent. They had to be involved in the first attempt of a standard IVF or ICSI program carried out in metropolitan France and registered between 1st January 1989 and 31st December 2005 (Rolland et al. 2013). They also had to provide freshly ejaculated sperm.

In theory, couples all over France had equal access to ARTs, as the first four attempts were fully covered by the Health Insurance, and Fivnat centers were set up all over the country (Fig. 1). The attempts were covered identically in public or private ART centers.

\section{Measurement methods}

Three indicators of semen quality were registered in the Fivnat database: sperm concentration (in millions of sperm per milliliter), total motility (in percentage of motile sperm) and morphology (in percentage of sperm with normal forms). Two spermiograms per individual were available: the check-up spermiogram, carried out mostly in a town laboratory prior to the attempt, and the attempt spermiogram, carried out in the ART center the day of the attempt. The date for the check-up spermiogram was not available, so only the attempt

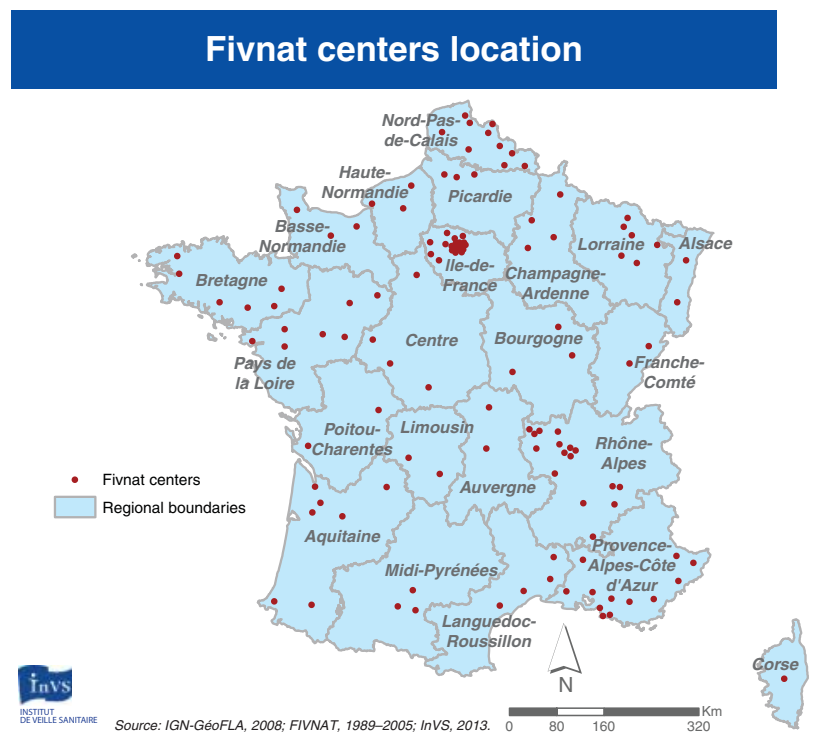

Figure 1 Location of Fivnat centers in metropolitan France that provided data between 1989 and 2005. spermiogram was studied. The methods used for the measurement of each sperm indicator were not available in the Fivnat database. For sperm concentration and motility, French experts confirmed that the methods have not changed noticeably during the study period (Rolland et al. 2013). Regarding morphology classification, a majority of the laboratories used David's classification during the study period (Blanchard et al. 2011).

\section{Men's location}

The Fivnat database did not register the couples' addresses, so the men were located using the address of the ART center where the attempt was performed. For this reason, the French metropolitan regions were chosen as the geographical scale for the spatio-temporal analyses. We assumed that couples were more likely to attempt ARTs within the regions where they lived. In order to check this assumption, we looked at the national hospital database in which oocyte retrievals were recorded since 2010. This enabled us to compare the women's dwelling locations and the locations of the fertility clinics they attended.

\section{Statistical analysis}

We studied the indicators of semen quality that were defined in the national study: concentration, motility, and morphology (Rolland et al. 2013). A Box-Cox transform (Box \& Cox 1964) was applied to sperm concentration for the residuals of the model to be normally distributed. Data for the three indicators of semen quality were aggregated by region and by month. A Gaussian observation model for each semen quality indicator was defined.

We used the spatio-temporal model introduced by Bernardinelli et al. (Bernardinelli et al. 1995, Schrödle \& Held 2011). To model data in space and time, a Bayesian model with parametric time trends was proposed. The linear predictor is decomposed additively into components depending on space, time or both. A main linear time trend and a differential time trend for each region are added to the spatial component. The age effect was taken into account. The main objective of this spatio-temporal model is to show how the slopes are positioned in between the regions. Additional details on the model are provided in Supplementary Methods, see section on supplementary data given at the end of this article. The inla program and the R package INLA were used (Martino \& Rue 2010).

The slopes and credible intervals for the 21 French metropolitan regions were compared with a null trend and the estimated overall linear trend. In a Bayesian analysis, a 95\% credible interval means that the probability of the parameter to belong to it is 0.95 . The slopes were mapped in order to visualize possible spatial trends. Maps were drawn using ESRI Basic ArcGIS for Desktop 10.0. Finally, for each indicator, the estimated linear trends for the 21 regions were shown to analyze together the slopes and the variations of the values.

\section{Results}

The number of men included in the study was generally higher in more populated regions (Ile-de-France, 
Table 1 Number of records by region and by indicator within the time period of data collection.

\begin{tabular}{|c|c|c|c|c|c|c|c|c|}
\hline \multirow[b]{2}{*}{ Region } & \multirow{2}{*}{$\begin{array}{c}\text { French } \\
\text { population } \\
\text { in } 1999^{\mathrm{a}}\end{array}$} & \multirow{2}{*}{$\begin{array}{l}\text { Percentage of } \\
\text { oocyte retrievals } \\
\text { performed in the } \\
\text { dwelling region of } \\
\text { couples in } 2010^{b}\end{array}$} & \multicolumn{2}{|c|}{ Concentration } & \multicolumn{2}{|c|}{ Motility } & \multicolumn{2}{|c|}{ Morphology } \\
\hline & & & $\begin{array}{l}\text { Record } \\
\text { number }\end{array}$ & Period & $\begin{array}{l}\text { Record } \\
\text { number }\end{array}$ & Period & $\begin{array}{l}\text { Record } \\
\text { number }\end{array}$ & Period \\
\hline Ile-de-France & 10952011 & 91.5 & 5465 & 1989-2005 & 6272 & 1989-2005 & 1699 & 1989-2005 \\
\hline Rhône-Alpes & 5645407 & 93.0 & 2911 & 1989-2005 & 2901 & 1989-2005 & 1257 & 1989-2005 \\
\hline $\begin{array}{l}\text { Provence-Alpes-Côte } \\
\text { d'Azur }\end{array}$ & 4502385 & 89.4 & 1975 & 1989-2003 & 1969 & 1989-2003 & 1303 & 1989-2003 \\
\hline Aquitaine & 2908359 & 84.6 & 1629 & 1989-2005 & 1649 & 1989-2005 & 1148 & 1989-2005 \\
\hline Pays de la Loire & 3222061 & 86.2 & 1152 & 1989-2005 & 1141 & 1989-2005 & 385 & 1989-2004 \\
\hline Bretagne & 2906197 & 90.0 & 963 & 1989-2005 & 960 & 1989-2005 & 508 & 1989-2001 \\
\hline Lorraine & 2310376 & 96.9 & 894 & 1989-2005 & 703 & 1989-2005 & 185 & 1991-2005 \\
\hline Midi-Pyrénées & 2551687 & 88.7 & 794 & 1989-2005 & 831 & 1989-2004 & 782 & 1989-2005 \\
\hline Nord-Pas-de-Calais & 3996588 & 98.2 & 690 & 1989-2005 & 659 & 1989-2005 & 283 & 1989-2004 \\
\hline Champagne-Ardenne & 1342363 & 77.3 & 657 & 1989-2004 & 670 & 1989-2005 & 551 & 1989-2005 \\
\hline Haute-Normandie & 1780192 & 93.9 & 648 & 1989-2005 & 632 & 1989-2005 & 570 & 1989-2005 \\
\hline Centre & 2440329 & 81.4 & 605 & 1989-2004 & 475 & 1989-2003 & 529 & 1989-2002 \\
\hline Alsace & 1724145 & 80.4 & 547 & 1989-2004 & 194 & 1989-2004 & 331 & 1990-1995 \\
\hline Franche-Comté & 1117059 & 94.9 & 530 & 1991-2005 & 531 & 1991-2005 & 339 & 1991-2001 \\
\hline Auvergne & 1308878 & 76.3 & 438 & 1989-2005 & 439 & 1989-2005 & 390 & 1989-2005 \\
\hline Languedoc-Roussillon & 2295648 & 83.5 & 401 & 1989-2005 & 359 & 1989-2005 & 23 & 1995-2003 \\
\hline Picardie & 1857481 & 82.4 & 365 & 1989-2004 & 371 & 1989-2004 & 177 & 1989-2004 \\
\hline Basse-Normandie & 1422193 & 98.3 & 261 & 1995-2004 & 258 & 1995-2004 & 69 & 1995-2000 \\
\hline Bourgogne & 1610067 & 89.9 & 257 & 1992-2004 & 256 & 1992-2004 & 174 & 1992-2004 \\
\hline Limousin & 710939 & 75.9 & 126 & 1993-2002 & 122 & 1993-2002 & 99 & 1993-2002 \\
\hline Poitou-Charentes & 1640068 & 92.1 & 122 & 1990-2005 & 121 & 1990-2005 & 1 & 1991-1991 \\
\hline
\end{tabular}

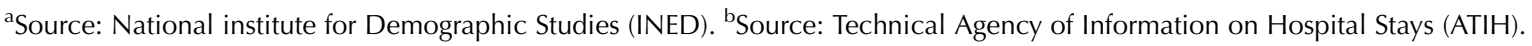

Rhône-Alpes, Provence-Alpes-Côte d'Azur, Pays de la Loire, and Aquitaine), except for Nord-Pas-de-Calais, and it was lower in less populated regions (Limousin and Poitou-Charentes) as shown in Table 1. This is consistent with the hypothesis that couples attempt ARTs within the regions where they live. The hospital data show that, in 2010, between 81.4 and $98.3 \%$ of the oocyte retrievals in each region were performed in couples located in the same region, except for three regions. In Limousin, Auvergne, and Champagne-Ardennes, the proportion is lower, but still $>75 \%$.

\section{Concentration}

The overall linear temporal trend for sperm concentration was significantly negative with an estimated value of -0.0049 (95\% credible interval: $-0.0076 ;-0.0021)$. All regions barring three showed a negative trend and nine regions had a significantly negative slope (Fig. 2). None of the regions had a significantly positive slope. Only one region, Aquitaine, had a linear trend stronger than the estimated overall trend.

Midi-Pyrénées had the lowest average estimated value in 1989, showed a decreasing trend and had still the lowest estimated value in 2005 as shown in Fig. 3.

Compared with the null slope, mapping of the results highlights that almost the whole of metropolitan France had a decreasing trend (warm colors (colors other than green)) for sperm concentration (Fig. 4), with particularly marked trends in the Northwest and Southwest.

\section{Motility}

The estimated overall temporal trend for motility was significantly positive, with an estimated value of +0.0309 (95\% credible interval: 0.0022; 0.0596). Eleven regions presented a significantly positive trend. Two regions, Nord-Pas-de-Calais and Bourgogne, had a significantly negative trend, the later having the highest. Compared with the overall trend, the regions HauteNormandie, Lorraine, Poitou-Charentes, and Auvergne had the highest positive slopes. Several regions had no significant trend. Among these were Ile-de-France, Pays de la Loire, Aquitaine, and Rhône-Alpes, all of which were regions with a large number of data (Supplementary Figure 1, see section on supplementary data given at the end of this article). No marked spatial trend is observable (Supplementary Figure 2). Regional estimated linear trends did not show any special feature (Supplementary Figure 3).

\section{Morphology}

The number of men studied for sperm morphology was much lower than that for the other indicators (Table 1), and some regions had very little data (BasseNormandie, Languedoc-Roussillon, Limousin, and Poitou-Charentes).

The overall temporal trend was significantly decreasing, with an estimated value of -0.0754 (95\% credible interval: $-0.0398 ;-0.1109)$. There was evidence of 




Figure 2 Estimated slope for sperm concentration between 1989 and 2005 for each region, adjusted for age, with 95\% credible interval, compared with the estimated overall national slope with $95 \%$ credible interval (red) and with zero slope (purple).

spatial heterogeneity. Several regions showed large credible intervals (Fig. 5). Fourteen regions had an estimated significantly decreasing trend. Two regions, Aquitaine and Midi-Pyrénées, showed a trend steeper than the overall trend. Two regions had an estimated positive trend (Franche-Comté and Bretagne).

Mapping of these results (Fig. 6) shows marked decreasing trends in the Southwest, Center, and East, except for Franche-Comté and Provence-Alpes-Côte d'Azur. Regional estimated linear trends did not show any special feature for the regions with a lot of data (Supplementary Figure 4, see section on supplementary data given at the end of this article).

\section{Discussion}

We performed a spatio-temporal analysis of the data on sperm quality, in a sample of 26609 men close to the general population of France, from 1989 to 2005. The results allowed comparing time trends in 21 metropolitan regions for the three sperm indicators: concentration, total motility, and morphology.

\section{Limits}

These results are based on the assumption that couples involved in ARTs mainly performed their first attempt within the region where they lived at the date of the attempt. We were able to confirm this hypothesis indirectly using hospital data, even though they were only available since 2010.

Moreover, we chose to use a spatio-temporal model that allowed adjusting - at least partially - for this limit. The model accounts for spatial correlation, temporal effects, and their interaction. A limitation of the model used is the assumption that the trend for each region is linear over time (Knorr-Held 2000). A generalized additive model was tested to explore possible non-linear regional trends for the three indicators of sperm quality (Wood 2006) and the linear hypothesis seemed to be reasonable.

The diversity in laboratory practices was addressed in the temporal study at the whole-country level (Rolland et al. 2013) using the data on a second spermiogram. Thus, even though we could not test the spatio-temporal model on this second spermiogram, as the location of the laboratories where it was performed was not available, we argue that center variation did not influence the trends. Otherwise for morphology, we argued in the previous study that the evolution of practices could have at least partially modified the temporal trend. Thus, this could have impacted our morphology results, especially if the known improvement of observers' accuracy did not occur simultaneously across all regions or centers.

Finally, the availability of small number of data in several regions and some large credible intervals implied that care must be taken while interpreting the results (Table 1).

\section{Interpretation of the results}

\section{Concentration}

During the study period, the sperm concentration decreased in all regions of France except three of them. One was constant and two showed a nonsignificant increase. The overall decrease in sperm concentration observed over the whole of France can therefore be observed at the regional level in France. This increases the importance of the results of the national study with regard to public health (Rolland et al. 2013). Such a pattern leads to the hypothesis that the decrease is the consequence of a global change in factors affecting the sperm concentration during the study period.

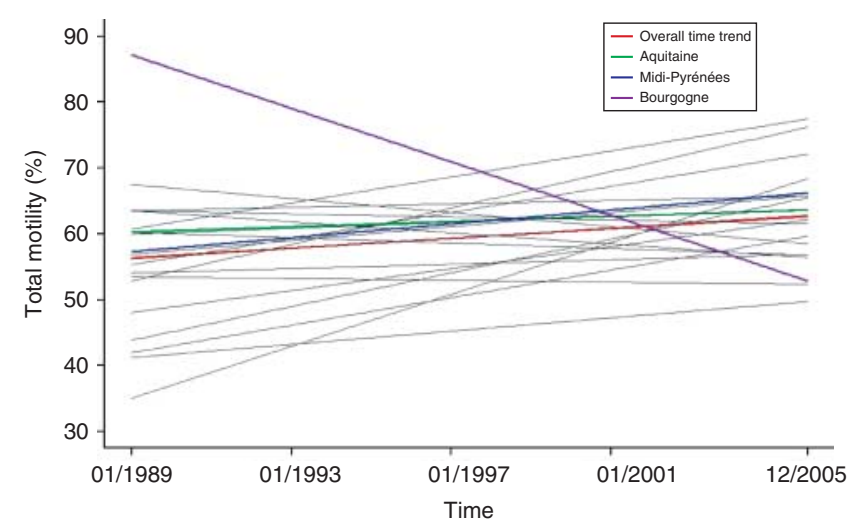

Figure 3 Estimated linear evolution of sperm concentration (in million sperms/ml) between 1989 and 2005, adjusted for age, for each region. 


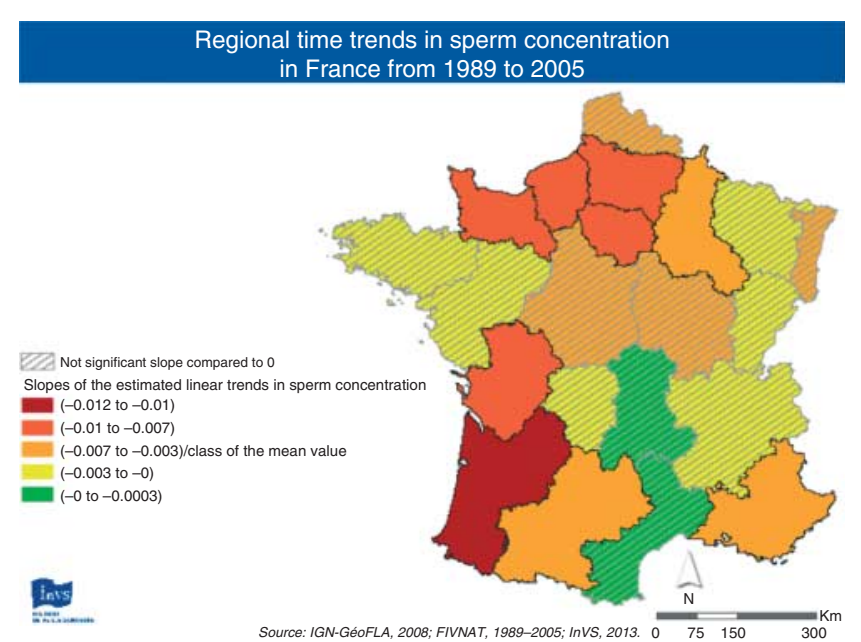

Figure 4 Map of the estimated linear trends for the sperm concentration between 1989 and 2005, adjusted for age (red, highest decrease; green, highest increase; and hatched, non-significantly different from 0 ).

Through this global pattern, the regions Aquitaine and Midi-Pyrénées clearly standout. Interestingly, in a previous French study on semen donors during the period of 1973-1993, the lowest values of sperm counts were observed in Toulouse, a Midi-Pyrénées' main city (Auger \& Jouannet 1997). But in this city, the trend for sperm concentration did not decrease between 1977 and 1992 in a sample of 302 sperm donors (Bujan et al. 1996).

\section{Motility}

Although the global trend for motility was steady, there were regional disparities. This high variability could partially be explained by more local factors. Little is known about the factors impacting motility, and epidemiological results are often more controversial for motility than for concentration and morphology regarding time trends (Rolland et al. 2013). Increasing and decreasing factors could act together. For example, coffee consumption, which could have increased during the study period, may increase motility (Sobreiro et al. 2005, Li et al. 2011), whereas BMI, stress, or several endocrine disruptors may impair it (Sharpe 2010, Li et al. 2011).

Only one region seems to stand out with an important significant decrease, the Bourgogne region. Noticeably, it showed the highest value for motility in 1989 (Supplementary Figure 3), and it fell under the national value in 2005. However, it must be noted that few data were available for this region (Table 1 ).

\section{Morphology}

As for concentration, it can be stated that the decreasing trend in sperm's normal morphology is observed in almost all regions of France, which leads to the same hypothesis. However, it has been discussed that improvement in observer accuracy could partly explain these trends (Rolland et al. 2013). In this study, very few data are available for some regions, so the results must be interpreted carefully.

Nevertheless, it is interesting to note that the two regions pinpointed for sperm concentration, Aquitaine and Midi-Pyrénées, are the same that showed slopes lower than the overall slope for morphology. Similarly, Bourgogne, pinpointed for sperm motility, showed the second highest negative slope (Fig. 5).

\section{Links with possible factors}

The global decrease in sperm concentration and morphology does not seem to be due to local factors, but most probably due to global changes either in environmental exposure or in lifestyle that would equally have an impact on men all over the country during the study period. As in most developed countries, the French population has been exposed to a growing number of chemicals via diverse routes of exposure since the 1950s. More than 800 substances are now suspected to be endocrine disruptor chemicals (EDCs; Bergman et al. 2012). Main EDCs are now found in biological matrices of French people (Casas et al. 2012, Frery 2013), some (non-dioxin-like PCB, pesticides and triclosan) at a level higher than that in other countries. Our results could therefore be consistent with the endocrine disruptor hypothesis, recently strengthened in an international report (Bergman et al. 2013).

Regarding lifestyle, the main factor known to both impact semen quality and to have increased in French men during the study period is overweight/obesity (Inserm 2006). On the other hand, tobacco smoking and alcohol drinking have decreased in French men (Salines et al. 2007).

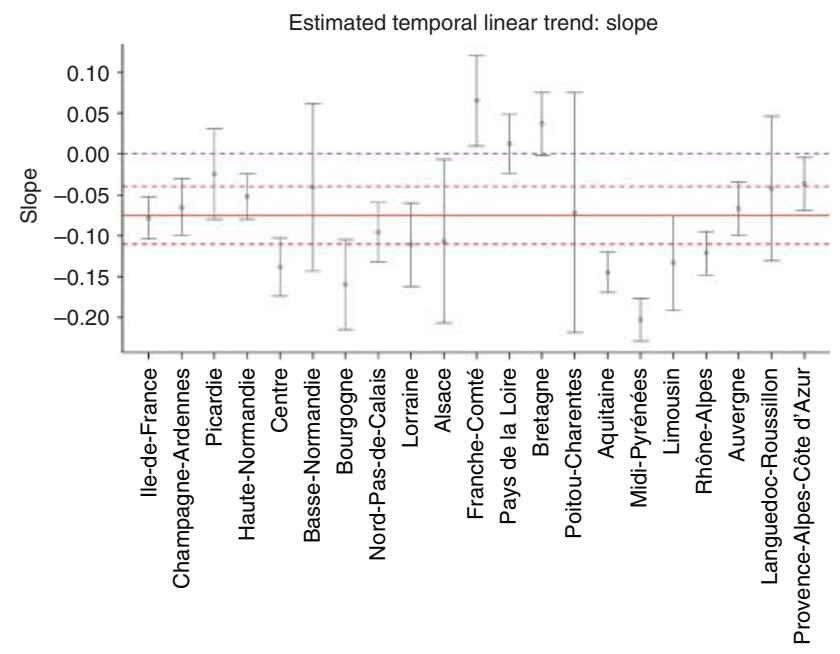

Figure 5 Estimated slope for sperm morphology between 1989 and 2005, adjusted for age, for each region with $95 \%$ credible interval, compared with the overall national slope with $95 \%$ credible interval (red) and with zero slope (purple). 


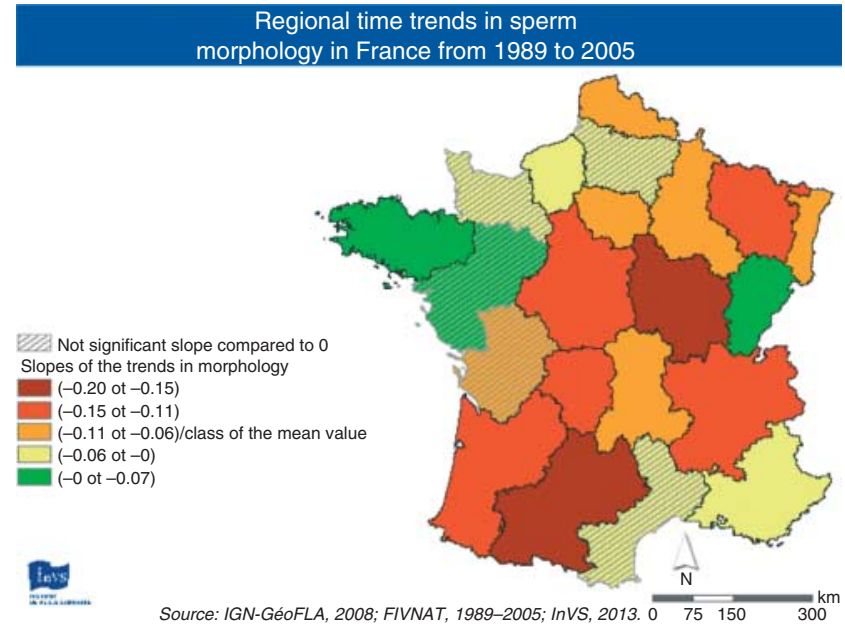

Figure 6 Map of the estimated linear trends of sperm morphology between 1989 and 2005, adjusted for age, (red, highest decrease; green, highest increase; and hatched, non-significantly different from 0 ).

Our results pinpoint two regions, Aquitaine and Midi-Pyrénées, that show a consistent pattern of strong decrease and low values for concentration and morphology. Regarding lifestyle, these two regions do not show specific patterns with regard to the average BMI. Regarding trends, the increase in BMI in Midi-Pyrénées is less than that in the rest of France, and the increase observed in Aquitaine is more or less similar to the national value (Salines et al. 2007). Furthermore, these two regions were not among those showing the highest rate of tobacco smoking or alcohol drinking (Salines et al. 2007). Local environmental factors could therefore contribute to the pinpointed trends in these regions.

Aquitaine is a populated region known for grape farming. It is the first French region in agricultural employment and the second with regard to the number of agricultural farms (Ministry of Food, Agriculture and Forest 2014). It is particularly studied with regard to pesticide exposures, which are expected to be higher for agricultural workers (Baldi et al. 2012). Industrial activity is concentrated in the area of Bordeaux, the main city.

Midi-Pyrénées is the first French region with regard to the number of agricultural farms and the second in agricultural surface (Ministry of Food, Agriculture and Forest 2012). It has diversified agricultural activity (wine, fruits, vegetables, and cereals), which is important, and a high population. There is noticeable Industrial activity in the main city area (Toulouse).

Among the possible factors contributing to marked decreasing trends in concentration and morphology, exposure of the general population to agricultural practices could be invoked in these two regions. A large number of pesticides are found to be potential EDCs and could affect semen quality (Bretveld et al. 2007). It would be interesting to focus on those used in the cultivation of grapevine. Indeed, application of pesticides is much more important in vine growing than in any other types of cultivation. Vine cultivation accounts for $20 \%$ of the total pesticides used for only $3 \%$ of the total French cultivated area (Expertise collective de I'Inserm 2013). Fungicides are by far the most employed but there are important disparities of practices among the French wineyielding regions (Ambiaud 2012). For example, vinclozolin is well known for its action on male fertility (Yu et al. 2004), even at early low-dose exposure (Eustache et al. 2009, Auger et al. 2010). This peculiar fungicide product, acting as an anti-androgen, was widely used in grapevine, fruit, and vegetable cultures from 1978 to 2007 in France, and is also increasingly suspected to have transgenerational effects (Auger et al. 2013, Skinner et al. 2013). The exposure period to this peculiar pesticide does not seem to be consistent with the TDS hypothesis of fetal exposure to EDCs. Indeed, as the average age of men included in the study sample was 35 years between 1989 and 2005, their mothers were expected to be pregnant on average - between 1954 and 1970. But it does not rule out the possible role of exposure after birth and, even if pesticide practices are unfortunately poorly documented in France, it is admitted that multiple other chemicals and high doses were intensively used since the 1950s (Expertise collective de l'Inserm 2013).

Levels of organophosphates, another family of insecticides suspected to affect sperm quality (Jurewicz et al. 2009, Martenies \& Perry 2013), were recorded during the period of 2006-2007 in the French general population. Interestingly, the levels were found to be significantly correlated with the proportion of soil area allocated for grapevine cultivation by the residence department (Frery 2013). This result supports the fact that agricultural practices for grapevine could locally contribute to the exposure of the general population to pesticides. Regarding Bourgogne, the results are less consistent. It is also an important wine-yielding region, but the proportion of soil area allocated for this activity is low.

Other important agricultural regions do not show the same marked decreasing trends. Noticeably, the regions Languedoc-Roussillon and Provence-Alpes-Côte d'Azur, which are also important wine- or fruit-yielding areas with large pesticide utilization, are not pinpointed in the trends. But protecting practices and chemicals utilization are different between the agricultural regions, depending on climate and pests (Bisault 2009).

\section{Conclusion}

The decreasing trend in sperm concentration and morphology, already shown at the French metropolitan territory level in a large sample of men close to the general population between 1989 and 2005, was observed at the level of almost all French regions. The causal factors therefore appeared to be existing in all parts of the country, which could be consistent with a global change in environmental exposure, especially according to the endocrine disruptor hypothesis 
(Bergman et al. 2012), and/or in lifestyle. However, the results at the regional level do not appear to support the lifestyle hypothesis.

Regarding motility, the national trend close to 0 seems to be the consequence of diverse regional trends, increasing or decreasing, without any spatial pattern. These could be due to randomly distributed trends or counteracting factors acting differently within the regions.

Regions such as Aquitaine, Midi-Pyrénées, and possibly Bourgogne appear to show stronger declining temporal trends with some consistency between the semen indicators. This needs to be confirmed with more precise data on men's actual location. In the light of the present results, perennial surveillance of semen quality, which allows assessing temporal and spatial trends in what is considered a public health biomarker (Jensen et al. 2009, Joffe 2010) and may even be a sensible biomarker of environmental exposure (Nordkap et al. 2012), appears to be necessary. In this context, development and comparison of consistent indicators among countries at a continental level may allow for further progresses in the understanding of patterns in sperm quality and their underlying causes.

\section{Discussion from meeting}

Shanna Swan (New York, USA): In your presentation, you stated that we studied sperm donors, whereas our study, and the European study, examined the geographical variations in sperm quality of partners of pregnant women. Therefore, our men had proven fertility and this is the most representative group. In such studies, it is important to separate fertile men from other males. It is interesting that your study shows a decline in sperm concentration of $1.9 \% /$ year which is exactly the same as the Carlsen study (Carlsen et al. 1992) and in our studies analyzing those data by geographical region (Swan et al. 1997, 2003).

J Le Moal (Saint-Maurice, France): You are right. Geographical variations in Europe and USA were not shown with donor samples; it was the case only within France. Our French study of more than 26000 men is the largest sample, close to the general population, studied in the world. The men were not selected on the basis of fertility outcomes as they were partners of totally sterile women, and the data covered the whole of France. That is why we argue that they were close to the general population of France. With regard to the magnitude of the decrease in concentration, we found that it is also close to the one found in the study of sperm donors from Paris during the period of 1973-1992 (Auger 1995), which showed a decline of $12.1 \%$ /year in sperm concentration.

\section{Supplementary data}

This is linked to the online version of the paper at http://dx.doi. org/10.1530/REP-13-0499.

\section{Declaration of interest}

The authors declare that there is no conflict of interest that could be perceived as prejudicing the impartiality of the research reported.

\section{Funding}

No specific funding was sought for this study. This study was exclusively financed with public funding by InVS. This article is based on work presented at the 7th Copenhagen Workshop on Endocrine Disrupters, which was supported by the Danish Ministry of the Environment - Environmental Protection Agency. Publication of this special issue was supported by the Society for Reproduction and Fertility. Dr J Le Moal received transport and accommodation costs to attend the COW meeting, and all other authors declare no relationship with the meeting sponsors.

\section{Acknowledgements}

The authors are grateful to all the ART centers for contributing to the Fivnat database. They thank the colleagues Nathalie Velly, Alain Le Tertre, Agnès Lefranc, Jean-Michel Thiollet, and Johan Spinosi from the Institut de Veille Sanitaire for their help and they also thank Catherine Poirot (Hôpital Tenon and Paris University).

\section{References}

Ambiaud E 2012 Fortes disparités de protection contre l'oïdium et le mildiou. AGRESTE La Statistique Agricole, October. http://www.agreste. agriculture.gouv.fr/IMG/pdf/primeur289.pdf

Auger J \& Jouannet P 1997 Evidence for regional differences of semen quality among fertile French men. Federation Francaise des Centres d'Etude et de Conservation des Oeufs et du Sperme humains. Human Reproduction 12 740-745. (doi:10.1093/humrep/12.4.740)

Auger J, Kunstmann JM, Czyglik F \& Jouannet P 1995 Decline in semen quality among fertile men in Paris during the past 20 years. New England Journal of Medicine 332 281-285. (doi:10.1056/NEJM1995020 23320501)

Auger J, Eustache F, Maceiras P, Broussard C, Chafey P, Lesaffre C, Vaiman D, Camoin L \& Auer J 2010 Modified expression of several sperm proteins after chronic exposure to the antiandrogenic compound vinclozolin. Toxicological Sciences 117 475-484. (doi:10.1093/toxsci/ kfq199)

Auger J, Le DD, Berges R, Doridot L, Salmon B, Canivenc-Lavier MC \& Eustache F 2013 Environmental levels of oestrogenic and antiandrogenic compounds feminize digit ratios in male rats and their unexposed male progeny. Proceedings. Biological Sciences 280 20131532. (doi:10.1098/ rspb.2013.1532)

Baldi I, Lebailly P, Rondeau V, Bouchart V, Blanc-Lapierre A, Bouvier G, Canal-Raffin M \& Garrigou A 2012 Levels and determinants of pesticide exposure in operators involved in treatment of vineyards: results of the PESTEXPO Study. Journal of Exposure Science \& Environmental Epidemiology 22 593-600. (doi:10.1038/jes.2012.82)

Bergman A, Heindel J, Jobling S, Kidd KA \& Zoeller RT 2012 State of the science of endocrine disrupting chemicals-2012, pp 1-296. WHO and UNEP. A Report. http://www.who.int/ceh/publications/ endocrine/en/

Bergman A, Heindel JJ, Kasten T, Kidd KA, Jobling S, Neira M, Zoeller RT, Becher G, Bjerregaard P, Bornman R et al. 2013 The impact of endocrine disruption: a consensus statement on the state of the science. Environmental Health Perspectives 121 A104-A106. (doi:10.1289/ehp. 1205448) 
Bernardinelli L, Clayton D, Pascutto C, Montomoli C, Ghislandi M \& Songini M 1995 Bayesian analysis of space-time variation in disease risk. Statistics in Medicine 14 2433-2443. (doi:10.1002/sim.4780142112)

Bisault L 2009 Bisault L 2009 A chaque vignoble ses traitements. AGRESTE La Statistique Agricole, September. http://agreste.agriculture.gouv.fr/ IMG/pdf_primeur230.pdf

Blanchard M, Haguenoer K, Apert A, Poret H, Barthelemy C, Royere D \& Guerif F 2011 Sperm morphology assessment using David's classification: time to switch to strict criteria? Prospective comparative analysis in a selected IVF population International Journal of Andrology 34 145-152. (doi:10.1111/j.1365-2605.2010.01066.x)

Box GEP \& Cox DR 1964 An analysis of transformations (with discussion). Journal of the Royal Statistical Society B, 211-252.

Bretveld R, Brouwers M, Ebisch I \& Roeleveld N 2007 Influence of pesticides on male fertility. Scandinavian Journal of Work, Environment \& Health 33 13-28. (doi:10.5271/sjweh.1060)

Bujan L, Mansat A, Pontonnier F \& Mieusset R 1996 Time series analysis of sperm concentration in fertile men in Toulouse, France between 1977 and 1992. BMJ 312 471-472. (doi:10.1136/bmj.312.7029.471)

Carlsen E, Giwercman A, Keiding N \& Skakkebaek NE 1992 Evidence for decreasing quality of semen during past 50 years. BMJ 305 609-613. (doi:10.1136/bmj.305.6854.609)

Casas M, Chevrier C, Hond ED, Fernandez MF, Pierik F, Philippat C, Slama R, Toft G, Vandentorren S, Wilhelm M et al. 2012 Exposure to brominated flame retardants, perfluorinated compounds, phthalates and phenols in European birth cohorts: ENRIECO evaluation, first human biomonitoring results, and recommendations. International Journal of Hygiene and Environmental Health.

Eustache F, Mondon F, Canivenc-Lavier MC, Lesaffre C, Fulla Y, Berges R, Cravedi JP, Vaiman D \& Auger J 2009 Chronic dietary exposure to a lowdose mixture of genistein and vinclozolin modifies the reproductive axis, testis transcriptome, and fertility. Environmental Health Perspectives 117 1272-1279. (doi:10.1289/ehp.0800158)

Expertise collective de I'Inserm 2013 Pesticides et santé. Synthèse et recommandations, pp 1-95. Inserm. A Report. www.inserm.fr/content/ download/72647/562921

Fisch H 2008 Declining worldwide sperm counts: disproving a myth. Urologic Clinics of North America 35 137-46. (doi:10.1016/j.ucl.2008. 01.001)

Frery N, Guldner L, Saoudi A, Garnier R, Zeghnoun A \& Bidondo M-A 2013 Exposition de la population francaise aux substances chimiques de I'environnement, tome 2, pp 1-176. InVS. A Report. http://www.invs. sante.fr/pmb/invs/(id)/PMB_11441

Inserm 2006 TNS health care Sofres Roche. Enquête épidémiologique nationale sur le surpoids et l'obésité, pp 1-54.

Jensen TK, Jacobsen R, Christensen K, Nielsen NC \& Bostofte E 2009 Good semen quality and life expectancy: a cohort study of 43,277 men. American Journal of Epidemiology 170 559-565. (doi:10.1093/aje/ kwp168)

Joffe $\mathbf{M} 2010$ What has happened to human fertility? Human Reproduction 25 295-307. (doi:10.1093/humrep/dep390)

Jorgensen N, Andersen AG, Eustache F, Irvine DS, Suominen J, Petersen JH, Andersen AN, Auger J, Cawood EH, Horte A et al. 2001 Regional differences in semen quality in Europe. Human Reproduction $\mathbf{1 6}$ 1012-1019. (doi:10.1093/humrep/16.5.1012)

Jurewicz J, Hanke W, Radwan M \& Bonde JP 2009 Environmental factors and semen quality. International Journal of Occupational Medicine and Environmental Health 22 305-329.

Knorr-Held L 2000 Bayesian modelling of inseparable space-time variation in disease risk. Statistics in Medicine 19 2555-2567. (doi:10.1002/10970258(20000915/30)19:17/18<2555::AID-SIM587>3.0.CO;2-)

Li Y, Lin H, Li Y \& Cao J 2011 Association between socio-psycho-behavioral factors and male semen quality: systematic review and meta-analyses. Fertility and Sterility 95 116-123. (doi:10.1016/j.fertnstert.2010.06.031)
Martenies SE \& Perry MJ 2013 Environmental and occupational pesticide exposure and human sperm parameters: a systematic review. Toxicology 307 66-73. (doi:10.1016/j.tox.2013.02.005)

Martino S \& Rue H 2010 Implementing Approximate Bayesian Inference using Integrated Nested Laplace Approximation: a manual for the INLA program. http://www.math.ntnu.no/ hrue/GMRFsim/manual.pdf

Ministry of Food, Agriculture and Forest 2012 Fiches filières grandes cultures DRAAF MidiPyrennées. Direction Régionale de l'Alimentation, de l'Agriculture et de la Forêt Midi-Pyrennées. http://draaf.midipyrenees.agriculture.gouv.fr/IMG/pdf/FicheFiliere_GrandesCultures_GP_ Def_cle092117.pdf

Ministry of Food, Agriculture and Forest 2014 L'agriculture aquitaine. La Direction Régionale de I'Alimentation, de l'Agriculture et de la Forêt d'Aquitaine. http://draaf.aquitaine.agriculture.gouv.fr/L-agriculture-aquitaine

Nordkap L, Joensen UN, Blomberg JM \& Jorgensen N 2012 Regional differences and temporal trends in male reproductive health disorders: semen quality may be a sensitive marker of environmental exposures. Molecular and Cellular Endocrinology 355 221-230. (doi:10.1016/j. mce.2011.05.048)

Rolland M, Le Moal J, Wagner V, Royere D \& De Mouzon J 2013 Decline in semen concentration and morphology in a sample of 26,609 men close to general population between 1989 and 2005 in France. Human Reproduction 28 462-470. (doi:10.1093/humrep/des415)

Salines E, de Peretti C \& Danet S 2007 Létat de santé de la population en France en 2006, pp 1-253. A Report. http://www.drees.sante.gouv.fr/ IMG/pdf/etat_sante_france_2006-2.pdf

Schrödle B \& Held L 2011 Spatio-temporal disease mapping using INLA. Environmetrics 22 725-734. (doi:10.1002/env.1065)

Sharpe RM 2010 Environmental/lifestyle effects on spermatogenesis. Philosophical Transactions of the Royal Society of London. Series B, Biological Sciences 365 1697-1712. (doi:10.1098/rstb.2009.0206)

Skinner MK, Haque CG, Nilsson E, Bhandari R \& McCarrey JR 2013 Environmentally induced transgenerational epigenetic reprogramming of primordial germ cells and the subsequent germ line. PLOS ONE 8 e66318. (doi:10.1371/journal.pone.0066318)

Sobreiro BP, Lucon AM, Pasqualotto FF, Hallak J, Athayde KS \& Arap S 2005 Semen analysis in fertile patients undergoing vasectomy: reference values and variations according to age, length of sexual abstinence, seasonality, smoking habits and caffeine intake. São Paulo Medical Journal 123 161-166. (doi:10.1590/S1516-31802005000400002)

Swan SH, Elkin EP \& Fenster L 1997 Have sperm densities declined? A reanalysis of global trend data Environmental Health Perspectives $\mathbf{1 0 5}$ 1228-1232. (doi:10.1289/ehp.971051228)

Swan SH, Brazil C, Drobnis EZ, Liu F, Kruse RL, Hatch M, Redmon JB, Wang C \& Overstreet JW 2003 Geographic differences in semen quality of fertile U.S. males. Environmental Health Perspectives 111 414-420. (doi:10.1289/ehp.5927)

Wood SN 2006 In Generalized Additive Models: an Introduction with $R$. Boca Raton: Chapman \& Hall/CRC.

Yu WJ, Lee BJ, Nam SY, Ahn B, Hong JT, Do JC, Kim YC, Lee YS \& Yun YW 2004 Reproductive disorders in pubertal and adult phase of the male rats exposed to vinclozolin during puberty. Journal of Veterinary Medical Science 66 847-853. (doi:10.1292/jvms.66.847)

Received 4 October 2013

First decision 28 October 2013

Revised manuscript received 17 February 2014

Accepted 20 February 2014 